\title{
Work In Progress: Improving Student Views of Medical Device Standards through Implementation in a First-term Biomedical Engineering Course
}

\section{Dr. Jeffrey A. LaMack, Milwaukee School of Engineering}

Dr. LaMack serves as undergraduate program director and course instructor in the Biomedical Engineering program in the Electrical Engineering and Computer Science Department at the MIlwaukee School of Engineering (MSOE). His areas of specialty include biophysical transport phenomena, biocomputing, physiology, and engineering design. Dr. LaMack holds a Ph.D. in Biomedical Engineering from Duke University, and he is an alumnus of the Biology Scholars Program of the American Society of Microbiology. Prior to becoming focused on engineering education, his research interests included hemodynamics and the study of how vascular cells respond to fluid forces and its implications in vascular pathologies.

\section{Dr. Larry Fennigkoh P.E., Milwaukee School of Engineering}

Dr. Larry Fennigkoh is a professor of biomedical engineering at the Milwaukee School of Engineering teaching graduate and undergraduate courses in medical instrumentation, biomedical engineering design, biomechanics, biostatistics, and human physiology. He is a Registered Professional Engineer and board certified in clinical engineering. He is also a member of the Institute of Electrical \& Electronic Engineers, Association for the Advancement of Medical Instrumentation, American College of Clinical Engineering, American Society for Engineering Education, and an inducted Fellow within both the American Institute for Medical and Biological Engineering, and the American College of Clinical Engineering.

Prof. Paul Licato 


\section{Work-In-Progress: Improving Student Views of Medical Device Standards Through Implementation in a First-Term Biomedical Engineering Course}

As undergraduate engineering students develop technical skills and an inclination to base design decisions on technical constraints, the application of engineering standards is often seen as a mandate of design instructors to satisfy accreditation requirements, rather than as a beneficial practice. When students carry this view into industry, medical device development and regulatory approval can be hindered, so industry is placing a greater value on students who appreciate and can effectively apply medical device standards. This work describes an attempt to introduce and implement medical device standards in a freshman-level introduction to biomedical engineering course and proposes a method to determine whether this early coverage of standards improves students' views about the importance of engineering standards and ability to later apply them appropriately in a capstone design project.

Education of Engineering Standards

Since the 2001-2002 accreditation cycle, undergraduate engineering curricula approved by the Engineering Accreditation Commission of ABET are required to incorporate engineering standards [1]. Current criteria require that curricula include "a culminating major engineering design experience that...incorporates appropriate engineering standards and multiple constraints” [2]. This requirement addresses demand from industry for engineering graduates to enter the workforce with knowledge of technical standards, particularly as a generation of baby-boomers with expertise in standardization retires. This demand encompasses a wide range of industries, including the medical field [3].

Despite the ABET requirement and practical need for undergraduate engineering programs to incorporate education of standards, a survey of universities in the United States in 2003 concluded that this topic is a low priority and that "the Schools of Engineering in the United Sates do yet not accept the critical nature of standards in the new $21^{\text {st }}$ century global economy" [4]. By contrast, several Asian countries place a much higher priority on education of standards, with some promoting awareness of standards as early as grade school [5].

To address deficiencies in standards education in the United States, a Standards in Education Task Force, made up of industry engineers and educators, worked to develop a set of recommendations in 2003. These recommendations suggested that engineering students should be given a comprehensive introduction to standards, gain familiarity with key standards organizations in their respective disciplines, study standards in the context of relevant case studies, and graduate with the ability to identify and apply relevant standards in the engineering design process [6]. These recommendations are consistent with those from a more recent panel discussion on standards education at the Capstone Design Conference in 2012, which further recognized that, to help achieve the desired proficiency of students to apply standards 
appropriately in their capstone design project, standards education should start earlier in the curriculum [7].

Several barriers to effective teaching of standards in engineering curricula have been cited, including difficulties in fitting the topic into tight curricula, lack of student and faculty accessibility to standards, lack of teaching resources dedicated to using standards, lack of faculty expertise in standards, and lack of student interest in standards [1], [7], [8]. A common approach to enhance the interest of students in standards is to provide examples to which the students can relate. For example, in biomedical engineering, Goldberg provides examples of standards applications in real medical devices. He cites a specific standard that ensures interchangeability of hypodermic needles and syringes made by different manufacturers as one tangible and relatable example [7].

\section{Development of an Immersive Experience with Standards in a Freshman Course}

To add further depth to student appreciation of standards early in the curriculum, we hypothesized that a hands-on mini-design project requiring students to address a standard in a freshman course will result in improved student appreciation for the importance of standards and ability to apply them later in their capstone design experience. The design project serves as a centerpiece for the course. Several activities and lectures early in the course are aimed at providing essential background knowledge and skills for the design project. This differs from our previous version of this course, which focused on early exposure to technical concepts but with no central theme or culminating project.

The ten-week three-credit course has two lecture hours and one two-hour laboratory session each week. Following training, students are given access to the department maker space, which features 3-D printers, circuit fabrication stations, and hand and power tools. Approximately 50\% of the lecture topics in the course provide a survey of biomedical engineering careers paths and our curriculum, and the remaining lecture topics relate to the design project. These include presentations covering computer-aided drawing, electric circuits, cardiovascular physiology, and engineering standards. Laboratory activities provide practice in developing skills in using SolidWorks (Dassault Systemes), making electrical measurements, fabricating circuits, and using 3-D printers. Students work in pairs on the term design project, for which the deliverables are a short written report and class presentation in the eleventh week exam period.

The design project addresses ECG lead wire connectors. It is motivated by a discussion of a case study involving several reported cases of patient injury or death attributed to electric shock resulting from misconnection of electrode lead wires into unlabeled 120 VAC line-cord plugs [9]. Students are shown images of unprotected electrode lead wires and the power cord plugs into which they geometrically fit to illustrate how such an avoidable mistake could be made by healthcare providers. 
Students are given an overview of the IEC 60601-1 standards and shown specific statements from the ECG Particular Standard (IEC 60601-2-25) that address the color code of ECG lead wires and the requirement that metal pins be recessed within connectors by at least $0.5 \mathrm{~mm}$ to prevent inadvertent electrical connection. Students are required to use a 3-D printer and appropriate tools to fabricate a connector block into which the ends of commercial ECG lead wires (Welch-Allyn, Skaneateles Falls, NY) can be securely inserted. The block is to incorporate a specific mating pin (appropriately recessed to comply with the standard) with which the ECG lead wire connector is to make reliable electrical contact. Students are required to demonstrate their connector and explain how the standard was addressed in their final presentation.

The next formal exposure to medical device standards in our curriculum is in a professional topics course in the fall quarter of the junior year, in which students are given three detailed presentations on the topic by faculty and industry experts. The students are then expected to incorporate standards appropriately in their four-quarter capstone design projects, which begins in the spring quarter of junior year.

Study Plan and Preliminary Results

The teaching module providing an immersive experience with medical device standards was first incorporated into the introductory biomedical engineering course in our curriculum in the fall 2018 quarter. A total of 61 students enrolled in the course across three sections taught by two instructors. All student groups successfully produced a 3-D printed prototype. The quality and sophistication of the designs varied, mainly owing to the wide range of previous experience students had with computer aided design. Grading was based primarily on the students' demonstration that they adequately considered the requirements, including those of the standards, during their design, rather than extra features they might have included. The majority of students addressed the standard, although several teams were not successful in executing it, suggesting some future refinement in the instruction of 3-D drawing and design is necessary.

The primary goal of the work is to improve students' appreciation for medical device standards and their ability to apply them by the time they graduate. To assess success in achieving this goal, a survey was constructed to ask students to rate their understanding of standards, their belief that the topic is important for biomedical engineers, and their confidence that they can apply standards in their career. The survey will be administered three times, the first one being at the beginning of the junior year prior to the professional topics course described above. This time point was chosen for the initial assessment, rather than directly after the freshman course, because it aligns with when assessment was performed for the previous cohort, allowing direct comparison. The second assessment is performed at the beginning of the spring quarter in the first capstone design course, and the final assessment occurs in the spring quarter of senior year at the conclusion of the design sequence. In addition, design instructors will be asked to rate students' abilities to apply standards appropriately to their respective design projects. All assessments will be given to two cohorts of students who took the introductory course without the standards module and the first two cohorts participating in the module. It is hypothesized that 
all performance measures will increase for the cohorts taking part in the module experience, reflecting a positive effect of introducing first-term engineering students to a hands-on project incorporating real medical device standards.

[1] W. Kelly, "Standards in civil engineering design education," Journal of Professional Issues in Engineering Education and Practice, vol. 134, no. 1, pp. 59-66, 2008.

[2] Criteria for Accrediting Engineering Programs. Accreditation Board for Engineering and Technology (ABET), November 24, 2018.

[3] B. Harding and P. McPherson, "What do employers want in terms of employee knowledge of technical standards and the process of standardization?," in Proceedings of the 2010 ASEE Annual Conference \& Exposition, Louisville, KY, USA, 2010, pp. 15.1364.1 - 15.1364.10.

[4] D. Purcell, "Report on a survey of schools of engineering in the United States concerning standards education," The Center for Global Standards Analysis, Spring 2004.

[5] H. de Vries and T. Egyedi, "Education about standardization: Recent findings," International Journal of IT Standards and Standardization Research, vol. 5, no. 2, pp. 11 - 16, 2007.

[6] A. Karim and J. McClain, "Standard education in technology programs", in Proceedings of the 2009 ASEE Annual Conference \& Exposition, Austin, TX, 2009, pp. 14.1070.1 14.1070.6.

[7] J. Goldberg, Capstone Design Courses Part II: Preparing Biomedical Engineers for the Real World. Morgan and Claypool Publishers, 2012.

[8] A. Khan, A. Karim, and J. McClain, "The state of the use of standards in engineering and technology education", in Proceedings of the 2013 ASEE Annual Conference \& Exposition, Atlanta, GA, USA, 2013, pp. 22.1233.1 - 23.1233.33.

[9] Risk of Electric Shock from Patient Monitoring Cables and Electrode Lead Wires. ECRI Institute Medical Device Safety Reports (MDSR), 1993. [Online]. Available: http://www.mdsr.ecri.org/summary/detail.aspx?doc_id=8161. [Accessed January 26, 2019]. 